DOI: 10.30519/ahtr.695159

Advances in Hospitality and Tourism Research (AHTR)

\title{
THE EFFECT OF ABUSIVE SUPERVISION ON SERVICE SABOTAGE: A MEDIATION AND MODERATION ANALYSIS
}

\author{
Mert GÜRLEK \\ School of Tourism and Hotel Management, Burdur Mehmet Akif Ersoy University, \\ Burdur, Turkey \\ ORCID: 0000-0002-0024-7746 \\ Murat YEŞILTTAŞ ${ }^{1}$ \\ School of Tourism and Hotel Management, Burdur Mehmet Akif Ersoy University, \\ Burdur, Turkey \\ ORCID: 0000-0001-7865-0407
}

\begin{abstract}
The main purpose of this study is to understand how abusive supervision affects service sabotage. In this context, the mediating role of job alienation was examined. In addition, other purpose of this research is to investigate whether organization-based selfesteem moderates the relationship between abusive supervision and job alienation. The study was carried out with the participation of 336 employees working in hotel companies in different regions of Turkey. It was revealed that abusive supervision impacts on job alienation and service sabotage. Moreover, the study results showed that job alienation affects service sabotage. Job alienation has a mediating role whereas organization-based self-esteem does not have a moderating role. Finally, this study contributes to the management literature by providing a cross-section on the consequences of abusive supervision.
\end{abstract}

Article History Received 26 February 2020

Revised 15 May 2020

Accepted 18 May 2020

\section{Keywords}

abusive supervision job alienation organization-based self-esteem service sabotage deviant behavior

\footnotetext{
${ }^{1}$ Address correspondence to Assoc. Prof. Murat Yeşiltaş, Burdur Mehmet Akif Ersoy University, School of Tourism and Hotel Management, Istiklal Campus, Burdur, TURKEY. E-mail: yesiltas.murat@gmail.com
} 


\section{INTRODUCTION}

Supervisors' verbal or nonverbal impairing behaviors, which do not include physical contacts, get more and more attention every day (Jian et al., 2012; Haar et al., 2016). What lies beneath this interest is the widespread occurrence of abusive supervision in work places. For example, it is pointed out that $27 \%$ of the employees are being abused at work (Tu et al., 2018). This rate is significantly high, translating abusive supervision into a topic that is worthy to be investigated. Although supervisors are expected to treat their subordinates in a good manner, they may sometimes use their powers and authorities to mistreat them (Mitchell \& Ambrose, 2007). When the importance of service quality is taken into consideration, harmful effects of abusive supervision become more evident in the hotel industry. The willful misconducts from supervisors may decrease the quality of service provided by employees and damage the image of the organization (Hon \& Lu, 2016; Yeşiltaş \& Gürlek, 2019). In this vein, it is important to understand the extent of damage abusive supervision may cause in the hotel industry.

Previous research points out that abusive supervision decreases helping behaviors (Zhao \& Guo, 2019), work engagement, customeroriented organizational citizenship behavior (Lyu et al., 2016a), organizational identification, proactive costumer service performance (Lyu et al., 2016b), and service performance (Jian et al., 2012), while it increases job dissatisfaction, deviant behaviors (Pan et al., 2018) and abusive subordinate behaviors (Hon \& Lu, 2016). Despite growing number of studies on abusive supervision in recent years, as mentioned above, only one study (Park \& Kim, 2019) examines the effect of abusive supervision on service sabotage. Service sabotage is a highly significant problem in hotel companies, so much that more than $90 \%$ of the employees report that service sabotage happens in their workplace every day (Harris \& Ogbonna, 2002). Thus, the relationship between abusive supervision and service sabotage needs to be investigated further.

In this study, it is argued that job alienation may have a key role in the relationship between abusive supervision and service sabotage. Therefore, the primary aim of the study is to explore whether job alienation has a mediating role. Despite the fact that job alienation is common among lower-level employees, still, not enough attention is given to the concept. (Nair \& Vohra, 2009). Job alienation is defined as employee's feeling of quit/avoidance/withdrawal from the workplace and the job (Ashforth, 1989). Being degraded and dismayed by abusive supervisors increases the possibility that subordinates psychologically break off with the job and 
become alienated (Lyuet al., 2016a). Treatments such as despising and punishment undermine a subordinate's psychological commitment to the job and the organization (Ashforth, 1997). If supervisors behave unethically, employees may feel that their association with the organization is broken and their feelings of alienation may intensify (Zoghbi-Manrique-de-Lara \& Viera-Armas, 2019). The Alienation Theory emphasizes that the negative experiences (e.g. deviation, abuse, exploitation) that employees have in their work places result in job alienation (O’Donohue \& Nelson, 2014).

Employees facing with exploitative and abusive supervision become alienated to their jobs (Behery \& Al-Nasser, 2016). Alienated employees feel discontented with their jobs and the likelihood of complaining about and harming the organization on purpose gets higher (Chiaburu et al., 2014). It is pointed out that job alienation is one of the reasons underlying employees' sabotage behaviors (Harris \& Ogbonna, 2010). The Alienation Theory emphasizes that alienation brings out normlessness, referring to the fact that the organizational norms become meaningless to the employee (Seeman, 1959). Accordingly, individuals who are alienated to their jobs may display sabotage behaviors by violating organizational norms without any hesitation. In sum, abusive supervision may lead employees to engage in more sabotage behaviors through increasing job alienation.

Supervisors' verbal or nonverbal harmful behaviors toward employees may result in job alienation (Shantz et al., 2015). However, under which circumstances abusive supervision causes job alienation remains unclear (Han et al., 2013). So, the secondary aim of the current study is to identify the circumstances under which abusive supervision results in job alienation. Organization-based self-esteem (OBSE) may alter the degree of relationship between abusive supervision and job alienation. OBSE refers to "the degree of an individual believing in him/herself to be capable, significant and worthy as an organizational member" (Pierce\& Gardner, 2004, p. 593). In organizational contexts, employees with high OBSE may display less negative reactions against abusive supervision when compared to the ones who have low level of OBSE. When employees are treated with abusive supervision, employees with low OBSE alienate to their job more than employees with high OBSE (Hui \& Lee, 2000). Hence, according to the Behavioral Plasticity Theory (Brockner, 1983, 1988) individuals with low self-esteem are more vulnerable to negative incidents they experience than those with high self-esteem. In other words, behaviors of individuals who have low self-esteem are further affected by negative experiences (Pierce et al., 1993). For example, Kiazad et al. (2010) identified the moderating role of OBSE in the effect of authoritarian leadership on abusive supervision. In 
this scope, this study claims that OBSE plays a moderating role in the effect of abusive supervision on job alienation.

The current study contributes to the literature on several aspects. First, it contributes to understanding the consequences of abusive supervision in the context of the hotel industry. Second, it puts forward how abusive supervision increases service sabotage by way of identifying the mediating role of job alienation Third, it reveals that OBSE does not play a moderating role in the effect of abusive supervision on job alienation in the context of the hotel industry.

\section{LITERATURE REVIEW}

\section{Abusive supervision and service sabotage}

Abusive supervision refers to "subordinates' perceptions of the extent to which supervisors engage in the sustained display of hostile verbal and nonverbal behaviors, excluding physical contact" (Tepper, 2000, p. 178). Among the typical examples of abusive supervision are yelling, having tantrums, humiliating or mocking someone in front of others, damaging someone's status, withholding information that someone needs, freezing someone out by not talking to, and to put pressure on ( $\mathrm{Xu}$ et al., 2012). Nowadays, abusive supervision is widespread in organizations and is one of the factors driving employees to exhibit deviant workplace behaviors (Wang et al., 2012).

According to the negative reciprocity norm of the Social Exchange Theory, when individuals perceive negative treatment, they reciprocate with negative treatment or behavior (Gouldner, 1960). Negative reciprocity norm emphasizes that individuals may perceive revenge as a right and suitable way of reciprocating against the negative treatment (Eisenberger et al., 2004). Employees suffering from abusive supervision bear the feeling of revenge, an act displayed in response to certain harm or wrong doing by another party. As a result of the perception of ill treatment, individuals may resort to deviant behaviors to take revenge (Liu et al., 2010). Victims of abusive supervision may utilize service sabotage, which is recognized as a type of deviant workplace behaviors, to retaliate against the organization they work for (Mitchell \& Ambrose, 2007). Service sabotage refers to service employees' intentional behaviors to give damage to costumer services (Harris \& Ogbonna, 2006). Slowing down service speed and behaving aggressively toward costumers are examples of service sabotage (Lee \& Ok, 
2014). To explain how the negative reciprocity between abusive supervision and service sabotage occurs, the Displaced Aggression Theory provides a useful theoretical foundation. Displaced aggression occurs when individuals display deviant workplace behaviors toward another party instead of the one responsible for the ill treatment they faced (Harris et al., 2011).

According to the Theory, individuals suffering from ill treatment do not direct their feelings of revenge toward the actual source due to fear of retaliation. Instead they direct those feelings to safer targets (Hoobler \& Brass, 2006). Employees confronting with abusive supervision tend to harm the organization or the organizational processes rather than harming their supervisors due to fear of retaliation (Burton et al., 2012). For example, a hotel employee might break the plates in the restaurant instead of responding to the supervisor when the supervisor gets angry and yells at him/her (Gürlek, 2020a). Although abusive supervision and service sabotage are widely observed in the hotel industry, there exists only one study investigating the relationship between the two variables. Park \& Kim (2019) confirm that there is a strong link between abusive supervision and service sabotage. Based on the aforementioned arguments, the following hypothesis is proposed:

H1. Abusive supervision affects service sabotage positively and significantly.

\section{Abusive supervision and job alienation}

The basis of the concept of alienation is rooted in the studies by Karl Marx on the effects of capitalist labor process on employees (Marx, 1963; Marx, 1969). Marx emphasizes that employees become alienated to their jobs because they are seen as slaves or physical entities for more labor by capitalists (Özer et al., 2019). Seeman (1959) provides a more contemporary interpretation of alienation, which constitutes the cornerstone for modern research on alienation. Seeman (1959) states that alienation is a multidimensional structure that consists of powerlessness, meaninglessness, normlessness, social isolation and self-alienation. Although later studies (Dean 1961; Blauner, 1964; Affinnih, 1997) provide new interpretations of multi-dimensional nature of alienation by decreasing the number of Seeman's dimensions, multi-dimensional structure has been criticized because it includes the antecedents of alienation rather than representing it. For example, it is argued that meaninglessness and powerlessness are not the dimensions but the antecedents of alienation (Twining, 1980; Kanungo, 
1982; Nair \& Vohra, 2012; Shantz et al., 2014). Nowadays, researchers suggest that alienation should be examined as a unidimensional factor (Nair \&Vohra, 2009, 2012; Shantz et al., 2014). In the scope of the current study, a unidimensional point of view is adopted and job alienation is defined as "the extent to which a person is disengaged from the world of work" (Hirschfeld \& Feild, 2000, p. 790).

Job alienation emerges as a consequence of the negative workplace experiences of an employee (Richman et al., 1996). Abusive supervision is a significant part of the negative experiences in question ( $\mathrm{Tu}$ et al., 2018). Studies show that abusive supervision is a significant antecedent of job alienation (Ashforth, 1994; Tepper, 2000). Hostile verbal and nonverbal behaviors can cause an individual become alienated to the job and the organization (Ashforth, 1997). Tyrannical behaviors by supervisors reflect central characteristics that break employees' connection with their social circles and the working environment (Schyns \& Schilling, 2013). When supervisors despise, humiliate and insult their subordinates, the subordinates have the feeling of isolation from their jobs (Akhtar \& Shaukat, 2016). The Alienation Theory assumes that negative experiences (deviation, abuse, exploitation) that employees have in their work places result in job alienation (O'Donohue \& Nelson, 2014). On the other hand, the Conservation of Resources Theory indicates that individuals tend to keep and protect the personal sources that they value. According to the Theory, individuals experience high levels of stress when their sources are damaged and lost, and as a result, they might disengage from the job (Hobfoll, 1989). Abusive supervision, as a factor which threatens individuals' personal resources, may cause individuals to be alienated from their jobs. Individuals confronting with abusive supervision may lose some emotional resources such as control, freedom and self-expression, which may break their connection with the job (Rousseau et al., 2014; Fatima et al., 2018). A few studies (Han et al., 2013; Finney et al., 2018) in literature highlight that abusive supervision increases job alienation. Based on the above-mentioned theoretical background, the following hypothesis is proposed:

H2. Abusive supervision affects job alienation positively and significantly.

\section{Job alienation and service sabotage}

Jermier (1988) points out that alienation is one of the significant antecedents of service sabotage. Sabotage can emerge as a manifestation of job alienation (Nair \& Vohra, 2012). To explain the relationship between job alienation and 
service sabotage, the Strain Theory (Merton, 1938; Mitchell, 1984) can be utilized. By applying for innovative solutions to cope with the strain resulting from alienation, individuals can render their lives more meaningful and different. For example, a husband who is dissatisfied with his relationship may become alienated to his wife and may display a behavior such as cheating on his wife with his secretary. Individuals who have been alienated to their jobs may exhibit deviant creative actions in their jobs although they have the chance to take up creative activities outside (e.g. hobbies, alternative activities) (Mitchell, 1984). Hence, individuals who have been alienated to their jobs may display sabotage behaviors by violating the organizational norms with no hesitation. A few studies in the literature indicate that alienation increase deviant behaviors (Shantz et al., 2015; Li \& Chen, 2018). Based on the above-mentioned theoretical foundations, the following hypothesis is proposed:

H3. Job alienation affects service sabotage positively and significantly.

\section{Mediating effect of job alienation}

In their longitudinal study, Brondolo et al. (2018) demonstrated that traumatic events in workplaces push employees behave negatively through the mediating effect of job alienation. The negative reciprocity norm of the Social Exchange Theory (Gouldner, 1960) claims that an individual reciprocates with negative behavior and attitude against the other party that treats him/her in an unfavorable manner. In other words, when individuals perceive unfavorable treatment (e.g. abusive supervision) they reciprocate with a negative attitude or behavior. The negative reciprocity norm points out that this reaction feeds on a feeling of revenge (Eisenberger et al., 2004). Individuals may direct their vengeance stemming from abusive supervision to their supervisors. Yet, as highlighted by the Displaced Aggression Theory (Hoobler \& Brass, 2006), these individuals generally direct their vengeance not to their supervisors but to the organization due to fear of retaliation. In this context, employees being exposed to abusive supervision may not retaliate directly against their managers, as they may have fear of further retaliation (e.g. layoff). Instead, they may prefer engaging in deviant behaviors that may harm the organization. To put it in a different way, employees can manage the negative reciprocity driven by abusive supervision and can display service sabotage which is a kind of deviant workplace behaviors (Tepper et al., 2008). Job alienation may explain how the negative reciprocity occurs between abusive supervision and employees. As a matter of fact, Li \& Chen (2018) find out that job 
alienation has a key role in individuals' displaying deviant workplace behaviors as a negative response resulting from the psychological contract breach. Alienation occurs as a response to negative organizational conditions and unfavorable treatment (Fatima et al., 2018). For example, Ashforth (1997) states that supervisors' tyrannical behaviors increase job alienation. Supervisors' verbal or nonverbal harmful behaviors may break the bond with the job and employees may become alienated (Akhtar \& Shaukat, 2016). Hence, they may engage in more sabotage behaviors. In sum, abusive supervision may increase service sabotage through giving rise to job alienation. Based on the above-mentioned theoretical discussion, the following hypothesis is proposed:

H4. Job alienation has a mediating effect on the relationship between abusive supervision and service sabotage.

\section{Moderating effect of OBSE}

Poor management styles (e.g. abusive, authoritarian) pave the way for subordinates to feel more vulnerable and get alienated to their jobs due to the weaknesses they have (Finney et al., 2018). When employees get defenseless against such kind of supervision, it becomes more likely that abusive supervision results in job alienation (Kiazadet al., 2010). With the purpose of verifying this argument, the moderating role of OBSE between abusive supervision and alienation is investigated in the current study. OBSE reflects the degree to which an employee feels important and valuable as an organizational member (Gardner \& Pierce, 1998). To investigate the moderating role of self-esteem between the negative behaviors that an employee is exposed to and his/her reactions to these behaviors, the Behavioral Plasticity Theory can provide a highly effective background (Pierce et al., 1993; Hui \& Lee, 2000; García-Cabrera \& GarcíaBarba Hernández, 2014; Ekrot et al., 2016). Employees with low OBSE are more defenseless against the negative incidents they are exposed to and the unfavorable experiences they have in the organization (Burton et al., 2011; Vogel \& Mitchell, 2017). The Behavioral Plasticity Theory (Brockner, 1983, 1988) claims that employees with lower self-esteem are more vulnerable and sensitive to negative incidents than the ones with higher levels of selfesteem are. When the level of self-esteem is low, negative experiences affect individual's behaviors more (Kiazadet al., 2010). Therefore, in scope of this study, employees with high OBSE levels are expected to display fewer negative reactions against abusive supervision than those with low OBSE levels. In this respect, when employees face with abusive supervision, 
employees with low levels of OBSE become more alienated to their jobs whereas those with high levels of OBSE become less job alienated. Based on the above-mentioned theoretical arguments, the following hypothesis is proposed:

H5. OBSE has a moderating effect upon the relationship between abusive supervision and job alienation.

\section{RESEARCH METHOD}

\section{Sample and procedures}

The data which were used in this study were obtained from the employees working in five-star hotels in Antalya, Muğla, and Ankara, which are among the provinces that have the highest bed capacity and attract most of the tourists in Turkey. For example, Antalya is in the first place, Muğla on the second and Ankara in the fifth place in the ranking of overall bed capacity (Ministry of Culture and Tourism, 2020). Therefore, these provinces are considered more suitable places for the research sample. The hotel companies in these provinces were selected via convenience sampling method. Researchers included hotels into the research via their personal connections. All of the five-star hotels selected are involved in the list of facilities with tourism operation certificate published annually by the Ministry of Culture and Tourism (2019). To collect data, human resources managers were contacted, the content of the research was explained, and they were asked to give consent to be involved in the research. 400 questionnaires were sent to a total of eight five-star hotels in Antalya $(n=3)$, Muğla (n=3) and Ankara (n=2). 50 questionnaires per hotel were distributed. Human resources managers were recommended to hand in questionnaire forms to the employees working in different departments. In addition, the managers were asked to inform employees not to provide any personal information while filling in the forms. Thus, the confidentiality in the study was ensured. 350 questionnaires were received back. Following the omission of the cases with missing values or unengaged responses, the study was completed with 336 questionnaire forms.

\section{Measures}

Researchers in this study used 15-item scale developed by Tepper (2000) to measure abusive supervision. This scale was also applied and validated by 
Ülbeği et al. (2014) in Turkish. A sample item is "supervisor tells me my thoughts or feelings are stupid". A five -point Likert scale was used $(5=$ frequently, 1 = never).

To measure OBSE, 10-item scale originally developed by Pierce et al. (1989) was used. This scale was also applied and validated by Akalın (2006) in Turkish. A sample item is "I am valuable at this organization". A fivepoint Likert scale was used ( $5=$ strongly agree, $1=$ strongly disagree).

A-10 item scale developed by Hirschfeld \& Feild (2000) was used to measure job alienation. The Turkish validity and reliability study of the scale was carried out by Özbek (2011). A sample item is "Most of work life is wasted in meaningless activity". A five-point Likert scale was used ( $5=$ strongly agree, 1 = strongly disagree).

The scale developed by Harris \& Ogbonna (2006) was used to measure service sabotage. The scale is unidimensional and composed of nine items. A five-point Likert scale was used ( $5=$ strongly agree, $1=$ strongly disagree). The adaptation of the scale items into Turkish was performed by Kanten et al. (2015). As a result of the analyses in the study, it was found that three items violated the unidimensional structure and did not provide the sufficient degree of factor reliability. Kanten et al. (2015) confirmed the unidimensional construct with six items. A sample item is "People here slow down service when they want to".

\section{Data analysis}

Preliminary statistics were obtained using SPSS 21.0 including data screening and preparation. PLS-SEM software was preferred to test the hypotheses developed in the study. The reason for preferring PLS-SEM is that it can also be used when the normality assumption is violated (Ali et al., 2018). As suggested by Hair et al. (2014) and Merli et al. (2019) kurtosis and skewness coefficients were calculated by using the kurtosis and skewness coefficients calculation software (https://webpower.psychstat.org/models/kurtosis). Mardia's multivariate skewness value $(\beta=2.782, p<0.01)$ and multivariate kurtosis value $(\beta=27.830, p>0.05)$ violated multivariate normality assumption. In the light of the results, it was concluded that the research data were not normally distributed. Therefore, Smart PLS v.3.2.7 statistical software and Partial Least Squares method were utilized for data analyses (Ringle et al., 2015). 


\section{RESULTS}

\section{Respondent characteristics and descriptive statistics}

After the omission of missing or incomplete surveys, the analysis process was carried out over 336 cases. $63 \%$ of the participants are male. A significant part of the respondents are young employees (over 70\%). More than half of the participants have at least high school degree (55\%), which is followed by associate degrees (20.8\%) and bachelor degrees (20.5). A significant number of the respondents work in the same hotel for 1 to 5 years $(43.8 \%)$, and this is followed by the ones who work in the same hotel for less than a year (39.1\%). $34.1 \%$ of the respondent employees are from the F\&B (Food and Beverage) department, $18.4 \%$ from the front office department and $17.4 \%$ from the kitchen department.

Table 1. Sample's Socio-Demographic Profile

\begin{tabular}{|c|c|c|c|c|c|}
\hline \multirow{2}{*}{ Gender } & Female & 37.0 & \multirow{4}{*}{$\begin{array}{l}\text { Job Tenure } \\
\text { (in this hotel) }\end{array}$} & Under 1 Year & 39.1 \\
\hline & Male & 63.0 & & $1-5$ & 43.8 \\
\hline \multirow{6}{*}{ Age } & Below 18 & 7.5 & & $6-10$ & 16.1 \\
\hline & $18-25$ & 33.2 & & $10+$ & 1.1 \\
\hline & $26-33$ & 30.4 & \multirow{8}{*}{ Department } & $F \& B$ & 34.1 \\
\hline & $34-41$ & 17.4 & & Kitchen & 17.4 \\
\hline & $42-49$ & 10.6 & & House Keeping & 8.9 \\
\hline & Above 49 & 0.9 & & Front Office & 18.4 \\
\hline \multirow{4}{*}{$\begin{array}{l}\text { Educational } \\
\text { Level }\end{array}$} & High School & 55.0 & & $\mathrm{HR}$ & 1.6 \\
\hline & Associate degree & 20.8 & & Accounting & 4.9 \\
\hline & Bachelor's degree & 20.5 & & Other & 14.8 \\
\hline & Master \& PhD & 3.6 & & & \\
\hline
\end{tabular}

\section{Common method variance (CMV)}

Researchers argue that CMV is a common problem for the studies in social sciences. It is indicated that there are quantitative and qualitative ways to eliminate this problem (Podsakoff et al., 2003). Anonymous application of surveys and not asking questions that might reveal the personal identities of the participants are among the qualitative techniques. In the current study, the suggestions proposed to eliminate CMV were taken into consideration. To identify whether CMV constitutes a problem, Harman's single factor test was applied and Variance Inflation Factor (VIF) values were checked. The results of the study indicate that the total variance explained was $66.4 \%$ and the first factor explained $34.4 \%$ of the total variance (less than $50 \%$ ). Moreover, VIF values were checked. The fact that 
VIF value for each latent variable is greater than 3.3 indicates multicollinearity problem, which signals that CMV constitutes a problem (Kock, 2015). Nevertheless, it is seen in the current study that VIF values for the latent variables range between 1.021 and 1.535 . Therefore, it can be stated that there is no CMV problem in this study.

Table 2. Outer Model Results

\begin{tabular}{|c|c|c|c|c|c|}
\hline Constructs & Item & Factor Loadings & CA & CR & AVE \\
\hline \multirow[t]{16}{*}{ Abusive Supervision } & & & 0.954 & 0.959 & 0.609 \\
\hline & ABSPV1 & 0.759 & & & \\
\hline & ABSPV10 & 0.801 & & & \\
\hline & ABSPV11 & 0.841 & & & \\
\hline & ABSPV12 & 0.789 & & & \\
\hline & ABSPV13 & 0.760 & & & \\
\hline & ABSPV14 & 0.816 & & & \\
\hline & ABSPV15 & 0.767 & & & \\
\hline & ABSPV2 & 0.792 & & & \\
\hline & ABSPV3 & 0.729 & & & \\
\hline & ABSPV4 & 0.792 & & & \\
\hline & ABSPV5 & 0.711 & & & \\
\hline & ABSPV6 & 0.805 & & & \\
\hline & ABSPV7 & 0.759 & & & \\
\hline & ABSPV8 & 0.799 & & & \\
\hline & ABSPV9 & 0.773 & & & \\
\hline \multirow[t]{6}{*}{ Job Alienation } & & & 0.823 & 0.875 & 0.585 \\
\hline & EMPAL4 & 0.749 & & & \\
\hline & EMPAL5 & 0.803 & & & \\
\hline & EMPAL7 & 0.728 & & & \\
\hline & EMPAL8 & 0.784 & & & \\
\hline & EMPAL9 & 0.758 & & & \\
\hline \multirow[t]{8}{*}{ OBSE } & & & 0.904 & 0.923 & 0.633 \\
\hline & OBSE10 & 0.717 & & & \\
\hline & OBSE4 & 0.764 & & & \\
\hline & OBSE5 & 0.774 & & & \\
\hline & OBSE6 & 0.827 & & & \\
\hline & OBSE7 & 0.848 & & & \\
\hline & OBSE8 & 0.833 & & & \\
\hline & OBSE9 & 0.798 & & & \\
\hline \multirow[t]{7}{*}{ Service Sabotage } & & & 0.902 & 0.924 & 0.671 \\
\hline & SERVSAB1 & 0.778 & & & \\
\hline & SERVSAB2 & 0.812 & & & \\
\hline & SERVSAB3 & 0.813 & & & \\
\hline & SERVSAB4 & 0.858 & & & \\
\hline & SERVSAB5 & 0.841 & & & \\
\hline & SERVSAB6 & 0.809 & & & \\
\hline
\end{tabular}




\section{Outer model assessment}

To validate convergent validity, factor loadings, Cronbach's Alpha (CA), Composite Reliability (CR) and Average Variance Extracted (AVE) values were calculated at first. The recommended values for factor loadings were set at $>0.70$, for the CA at $>0.70$, for the AVE at $>0.50$ and for the CR at $>0.70$ (Ali et al., 2018; Hair et al., 2014). Preliminary analyses indicated that some factor loadings were below the accepted cut-off values (5 items in Job Alienation scale and 3 items in OBSE scale) and since these values affected the reliability values, they were excluded from the analyses. When Table 2 is analyzed, it is seen that all values range between the cut-off values.

Discriminant validity means that each variable measured in a study has lower correlation than the other related constructs. In this study, for discriminant validity assessment, Fornell \& Larcker's (1981) criteria and Heterotrait-Monotrait Ratio (HTMT) were calculated. As seen in Table 3, the square root of AVE values (figures in bold) are greater than the correlation of each related latent variable. In addition, Henseler et al. (2015) point out that HTMT value is more reliable in the context of discriminant validity assessment. Values at and below 0.90 thresholds indicate that criteria validity is provided (Rodríguez-Victoria et al., 2017). It is seen in Table 3 that the values range between the accepted cut-off points, which reveals that the measurement constructs are valid and reliable. In this respect, in the following section, the structural model test will be carried out based on these constructs.

Table 3. Discriminant Validity

\begin{tabular}{llllll}
\hline Fornell - Larcker Criteria & & & & \\
& 1 & 2 & 3 & 4 \\
Abusive Supervision & $\mathbf{0 . 7 8 0}$ & & & \\
Job Alienation & 0.592 & $\mathbf{0 . 7 6 5}$ & & \\
OBSE & -0.313 & -0.392 & $\mathbf{0 . 7 9 6}$ & \\
Service Sabotage & 0.570 & 0.438 & -0.215 & $\mathbf{0 . 8 1 9}$ \\
\hline Heterotrait-Monotrait Ratio & & & & \\
& 1 & 2 & 3 & 4 \\
Abusive Supervision & & & & \\
Job Alienation & 0.663 & & & \\
OBSE & 0.328 & 0.436 & & \\
Service Sabotage & 0.609 & 0.505 & 0.229 & \\
\hline
\end{tabular}

The square roots of AVE values are shown in bold. Shaded boxes are the standard reporting format for HTMT procedure. 


\section{Inner Model Estimates (Hypothesis Testing)}

To test the research hypotheses Smart PLS 3.0 software was utilized. For the calculation of statistically significant path coefficients 5000 iterations and bootstrapping methods were used.

As in CB-SEM (covariance-based structural equation model) models, conventional indices do not evaluate the model as a whole in PLS SEM models. Hair et al. (2014) argue that $\mathrm{R}^{2}$ is an important variable for the evaluation of models' exploratory powers. PLS-SEM path model aims at maximizing the $\mathrm{R}^{2}$ of endogenous latent variable. Therefore, in the study it is aimed to have a greater value. In studies, $0.25,0.50,0.75$ values are assessed respectively as small, moderate and large (Hair et al., 2014). In Table $4, \mathrm{R}^{2}$ values of endogenous variables are provided. According to this, abusive supervision explained $39.8 \%\left(\mathrm{R}^{2}=0.398\right)$ of the variance in job alienation and $34.1 \%\left(\mathrm{R}^{2}=0.341\right)$ of the variance in service sabotage. In the study, the $\mathrm{R}^{2}$ values for inner variables were above 0.25 and this indicated that the model was substantial (Hair et al., 2014). Merli et al. (2019) state that another value to be used in PLS models is the standardized root mean square residual (SRMR). In this study, SRMR value was found 0.056 and accepted as substantial since it was below the cut-off value 0.080 .

It is important to know the extent to which an exogenous latent variable contributed to endogenous latent variable's $R^{2}$ value (Ali et al., 2016). In other words, the exploratory power of exogenous variables on endogenous variables should be evaluated. In this regard, effect sizes $\left(f^{2}\right)$ values should be determined. Effect sizes $\left(f^{2}\right)$ are calculated to assess how much a predicting variable contributes to an endogenous variable's $\mathrm{R}^{2}$ value (Ali et al., 2016). The effect size $\left(f^{2}\right) 0.02,0.15$ and 0.35 is small, moderate and large, respectively (Cohen, 1988). The effect sizes $\left(f^{2}\right)$ presented in the Table 4.

As indicated before, unlike CB-SEM software, PLS-SEM cannot provide overall goodness of fit indices. Although $\mathrm{R}^{2}$ is one of the basic evaluation measures, Goodness-of-Fit (GoF) value is among the fundamental evaluation measures, as well. This value is obtained by making use of the geometric mean of the average communality and the average of $\mathrm{R}^{2}$ of the endogenous variables (Ali et al., 2016). In their evaluation of GoF values, Hoffmann \& Birnbrich (2012) state that the cutoff values are $\mathrm{GoF}_{\text {small }}=0.1, \mathrm{GoF}_{\text {medium }}=0.25$ and $\mathrm{GoF}_{\text {large }}=0.36$. In this study, GoF was 0.480 . Therefore, it can be indicated that the level of goodness-offitness is high global model fit. 
In addition, in PLS models, Stone-Geisser $Q^{2}$ values (Geisser, 1974; Stone, 1974) are effectively used for predictive relevance by blindfolding test (Akter et al., 2011). In line with the suggestions from the literature (Henseler et al., 2009), $\mathrm{Q}^{2}$ values were calculated using cross-validated redundancy procedures. As Hair et al. (2017) suggest, when $\mathrm{Q}^{2}$ value is bigger than 0 , it means that model has predictive relevance whereas when a $\mathrm{Q}^{2}$ value less than 0 model does not have predictive relevance. As shown in Table 4, $\mathrm{Q}^{2}$ for job alienation is 0.227 and $\mathrm{Q}^{2}$ for service sabotage is 0.242. According to this result model has acceptable predictive relevance.

Table 4. Results of research hypotheses

\begin{tabular}{|c|c|c|c|c|}
\hline Hypotheses & $\beta$ & t-value & Decision & $f^{2}$ \\
\hline Abusive Supervision $\rightarrow$ Job Alienation & 0.522 & $11.418^{*}$ & Supported & 0.402 \\
\hline Job Alienation $\rightarrow>$ Service Sabotage & 0.156 & $2.566^{* *}$ & Supported & 0.024 \\
\hline Abusive Supervision $\rightarrow$ Service Sabotage & 0.478 & $7.517^{*}$ & Supported & 0.225 \\
\hline Abusive Supervision*OBSE $->$ Job Alienation & 0.002 & 0.338 & Not Supported & 0.001 \\
\hline Bootstrapping Results for Indirect Effects & $\beta$ & t-value & Decision & $\begin{array}{l}95 \% B C a L L C I \\
-U L C I\end{array}$ \\
\hline $\begin{array}{l}\text { Abusive Supervision }->\text { Job Alienation }-> \\
\text { Service Sabotage }\end{array}$ & 0.081 & 2.429 & Supported & 0.029-0.138 \\
\hline$R^{2}$ Results & \multirow{3}{*}{\multicolumn{4}{|c|}{$\begin{array}{l}Q^{2} \text { Results } \\
\text { Job Alienation : } 0.227 \\
\text { Service Sabotage }: 0.242\end{array}$}} \\
\hline Job Alienation : 0.398 & & & & \\
\hline Service Sabotage $\quad: 0.341$ & & & & \\
\hline
\end{tabular}

In the study, after evaluating the outer and inner model, hypothetical relationships in structural model were tested. First, the effect of abusive supervision on job alienation was tested and the hypothesis was supported $(\beta=0.522 ; t=11.418)$. Second, it was found out that job alienation had effect on service sabotage $(\beta=0.156 ; t=2.566)$. Third, it was revealed that abusive supervision affected service sabotage positively $(\beta=0.478 ; t=7.517)$. Thus, $H_{1}$, $\mathrm{H}_{2}$, and $\mathrm{H}_{3}$ were supported (Table 4).

In the research, the bootstrapping method proposed by Preacher \& Hayes (2008) was used to determine the mediating role of job alienation upon the effect of abusive supervision on service sabotage. According to Table 4, job alienation has a mediation role upon the effect of abusive supervision on service sabotage $(\beta=0.081 ; t=2.429$; $L L C I=0.029-\mathrm{ULCI}=0.138)$. Thus, $\mathrm{H}_{4}$ is supported. Zhao et al. (2010) indicate that the existence of the direct and indirect effect $(\mathrm{a} \times \mathrm{b})$ point out complementary mediation. Since the direct and indirect effects in the current study are significant, it can be highlighted that complementary mediation does exist in this study. 
This study hypothesized that OBSE has a moderation role upon the effect of abusive supervision on job alienation. To analyze the effect of moderation variable, PLS-SEM product-indicator approach was used. PLS enables to validate the theory and more accurate calculation of moderation effect by calculating the errors in estimated correlations (Henseler \& Fassott, 2010). As seen in Table 4, OBSE does not have a moderating effect on the relationship between abusive supervision and job alienation. This reveals that the level of OBSE, whether it is high or low, does not change the effect of abusive supervision on job alienation. Therefore, $\mathrm{H}_{5}$ is not supported.

\section{DISCUSSION AND CONCLUSION}

\section{Evaluation of the Findings}

In this study, it is found that abusive supervision has positive effect on service sabotage $\left(\mathrm{H}_{1}\right)$. This finding shows parallelism with the findings of Park \& Kim (2019). In addition, it is also in line with the negative reciprocity norm of the Social Exchange Theory (Gouldner, 1960) and Displaced Aggression Theory (Hoobler \& Brass, 2006). Accordingly, employees who encounter with abusive supervision may negatively reciprocate against the organization through service sabotage. The negative reciprocity between abusive supervision and service sabotage can be explained on the basis of the Displaced Aggression Theory. Individuals having the feeling of vengeance resulting from the ill treatment they have been exposed to may displace their aggressions toward the organization, which is perceived as a safer, instead of the actual source of ill-treatment due to fear of retaliation.

The results obtained in the current study showed that abusive supervision had a positive effect on job alienation $\left(\mathrm{H}_{2}\right)$. In accordance with the Theory of Conservation of Resources (Hobfoll, 1989), it was revealed that employees could not preserve their personal resources and experience job alienation when they face abusive supervision. Abusive supervisors cause their subordinates run out of their resources by humiliating them in public or threatening them to lose their jobs, which results in employees' suffering from job alienation.

Another finding in the current study indicated that job alienation had a positive effect on service sabotage $\left(\mathrm{H}_{3}\right)$. This is in line with the Strain Theory (Merton, 1938; Mitchell, 1984). Accordingly, because of the strain that result from job alienation, employees may display deviated behaviors. In addition, job alienated individuals take organizational norms into 
consideration less (Shantz et al., 2015) and, consequently, they may display more sabotage behaviors. The findings also showed that job alienation mediates the relationship between abusive supervision and service sabotage $\left(\mathrm{H}_{4}\right)$. According to this finding, by increasing the degree of employees' job alienation, abusive supervision increased service sabotage. In other words, alienation plays a key role in directing negative behaviors resulting from abusive supervision to the organization. In this study, it was found out that OBSE was not a moderator variable between abusive supervision and job alienation $\left(\mathrm{H}_{5}\right)$. Accordingly, OBSE neither enhanced nor reduced the effect of abusive supervision on job alienation. In other words, the effect of abusive supervision on job alienation does not depend on OBSE.

The research results indicate that OBSE has no moderating effect in this study. Thus, based on the abusive supervision's negative effect, employees may have alienation without considering OBSE. It can be inferred that this finding might have emerged as a result of the research context. For example, there is a high personnel turnover in the hotel industry and many employees do not stay in the same organization for a long time (Aksu, 2004). In the context of the current study, hotel employees did not consider whether their organization valued them as an organization member or not. Besides, they did not work for a long time in the same organization. Therefore, it is not expected that OBSE perception creates a significant effect on employees' behaviors. As seen in Table 1,39.1\% of employees work less than one year and 1.1\% work more than ten years in the same organization.

\section{Theoretical contributions}

This study contributes to the literature on several aspects. First, one of the primary contributions is that the antecedents that affect service sabotage are investigated. In literature, there are few studies on service sabotage, which have been carried out with different aims and theoretical backgrounds (Lee \& Ok, 2014; Yeşiltaş \& Tuna, 2018; Zhou et al., 2018; Park \& Kim, 2019). In this respect, this study contributes to the expansion of the related literature on service sabotage. Second, in the study, the effect of abusive supervision on job alienation, which has been ignored in the literature so far, is examined and the consequences of abusive supervision are expanded. In the scope of the study, not only the literature on abusive supervision is extended but also one of the antecedents of job alienation, which may produce significant results in managements, is investigated. 
Third, unlike the other studies conducted in the context of the hotel industry, the effect of job alienation on service sabotage is examined in this study. Service sabotage is not only a concept that has managerial reflections in the hotel industry but also among the behaviors that negatively reflect on business performance. Therefore, its antecedents should be treated carefully and suitable solutions should be found. Hence, the findings of this study contribute to the literature by revealing that job alienation increases service sabotage.

Fourth, alienation has turned into a concept that has almost been forgotten in mainstream management studies (Shantz et al., 2015). Chi et al. (2018) point out that it would be fruitful to investigate mediation processes in the relationship between abusive supervision and service sabotage. Thus, the current study contributes to the literature by proving that job alienation has a mediating role upon the effect of abusive supervision on service sabotage.

The final theoretical contribution of the study is that OBSE does not have a moderation role on the relationship between abusive supervision and job alienation. The studies, which were implemented in the other industries, indicate that OBSE has a moderator role on the relationships between negative incidents and experiences confronted by employees and their behaviors (Kiazad et al., 2010; Burton et al., 2011). Unlike the previous researches, this study demonstrates that OBSE does not have a moderator role. According to this result, the perception of OBSE is not considered as a crucial factor which may lessen the negative experiences of the employees. Thus, this study contributes to the literature. This can be explained with the dynamics of the hotel industry. Characteristics that belong to the hotel industry such as long working hours, low wages, and job insecurity (Jung \& Yoon, 2014; Gürlek, 2020a) may prevent individuals feel themselves important in the organization. And this may make the role of OBSE between the two variables insignificant.

\section{Managerial Implications}

The findings of the study show that abusive supervision increases job alienation and service sabotage. Supervisors can apply the following suggestions to eliminate the serious consequences of abusive supervision. The first step can be to identify the ones who display abusive supervision (Hussain \& Sia, 2017; Thau \& Mitchell, 2010). Superiors' ill-treatment to their subordinates, which is a kind of work place aggression, is not one of 
the specific interpersonal problems that can be solved by the victim (Pan et al., 2018). In this sense, for the solution of the problems that abusive supervision has created, problem-reporting centers can be established in organizations. Additionally, training for behavior control, anger management and communication skills can be arranged for the supervisors who have problems with employees or who display hostile verbal and nonverbal behaviors. Besides, for employees who are being supervised with appropriate leadership styles, alienation is not a matter of question (Di Pietro \& Pizam, 2008). So, organizations should choose their supervisors carefully and should not employ the ones who have shown negative tendencies in the tests administered at employment procedures to prevent abusive supervision. In this regard, selective recruitment practices are recommended for organizations (Gürlek, 2020b).

The findings of the study indicate that job alienation has an impact on the formation of service sabotage in the organization. Job alienation is a problem that must be dwelled upon by organizations, because this problem can cause individuals to put less effort and energy in the organization (Santas et al., 2016) while, at the same time, it can increase individuals' stress levels within the organization.

Job alienation shows that another mechanism has a significant role in the relationship between abusive supervision and service sabotage. The findings point out that abusive supervision triggers job alienation, which affects service sabotage in turn. Hence, this study can help organizations understand how abusive supervision affects service sabotage.

High level of OBSE does not have a decreasing effect on the relationship between abusive supervision and service sabotage. Accordingly, abusive supervision from the supervisors of the organization is so devastating that individual's feeling important and valuable in the organization does not minimize the negative consequences of abusive supervision. Moreover, in the hotel industry, employee turnover rate is considerably high, that is, employees change their jobs very frequently (Aksu, 2004). Therefore, employee behaviors may be shaped not by the views of the organization regarding their importance but by the actions of their supervisors (Gürlek \& Uygur, 2020). In this respect, OBSE may not play a moderator role. 


\section{Limitations and Directions of Future Research}

This study has several limitations. First, since self-reporting scales are used, CMV can turn into a factor that has to be considered (Podsakoff et al., 2003). To eliminate the CMV in the study, Harman's single factor test and VIF values were used. However, future studies can control CMV better by applying time-lagged data collection method. Second, this is a cross sectional study. Thus, there are no causality claims. Researchers are suggested to carry out more in-depth investigations for causal effects by obtaining longitudinal data.

Third, the abusive supervision scale utilized in the study consists of subjective statements. This is an important issue in that they could be perceived differently by different individuals. Xiaqi et al. (2012) state that abusive supervision is related to perception and add that "one subordinate may view a supervisory action as abusive, another may not" (p. 258). This view can be valid both at organizational environments and in the context of different societies. When this is taken into consideration, this may bring out a generalizability problem regarding the leadership differences between Western societies and others which are paternalist and collectivist and in which power distances are distinct such as Turkey. Thus, retesting the model in different societies is suggested. On the other hand, this study examined the moderator role of OBSE within the framework of some limitations. For future studies, it is recommended to investigate the moderator role of OBSE in the relationship between abusive supervision and service sabotage.

\section{REFERENCES}

Affinnih, Y. H. (1997). A critical reexamination of alienation. The Social Science Journal, 34(3), 383-387.

Akalın, Ç. (2006). Duygusal örgütsel bağhllı̆̆ın gelişmesinde çalışanların algıladığı örgütsel destek ve ara bir değişken olarak örgüt temelli öz-saygi. Unpublished master's thesis, Hacettepe University, Ankara, Turkey.

Akhtar, A., \& Shaukat, K. (2016). Impact of petty tyranny on alienation from work: Role of self-esteem and power-distance. Global Journal of Flexible Systems Management, 17(3),275-285.

Akter, S., D'Ambra, J., \& Ray, P. (2011). An evaluation of PLS based complex models: the roles of power analysis, predictive relevance and GoF index. Proceedings of the 17th Americas Conference on Information Systems (AMCIS2011) (pp. 1-7). Detroit, USA: Association for Information Systems.

Aksu, A. (2004). Turnover costs: Research among five-star hotels in the city of Antalya, Turkey. Tourism Analysis, 9(3), 207-217. 
Ali, F., Amin, M., \&Cobanoglu, C. (2016) An integrated model of service experience, emotions, satisfaction, and price acceptance: An empirical analysis in the Chinese hospitality industry. Journal of Hospitality Marketing \& Management, 25(4), 449-475.

Ali, F., Rasoolimanesh, S.M., Sarstedt, M., Ringle, C.M., \&Ryu, K., 2018. An assessment of the use of partial least squares structural equation modeling (PLS-SEM) in hospitality research. International Journal of Contemporary Hospitality Management, 30(1), 514-538.

Ashforth, B. (1994). Petty tyranny in organizations. Human Relations, 47(7), 755-778.

Ashforth, B. E. (1989). The experience of powerlessness in organizations. Organizational Behavior and Human Decision Processes, 43(2), 207-242.

Ashforth, B. E. (1997). Petty tyranny in organizations: A preliminary examination of antecedents and consequences. Canadian Journal of Administrative Sciences, 4(2), 126140.

Behery, M., \& Al-Nasser, A. (2016). Examining the impact of leadership style and coaching on employees' commitment and trust mediation effect of bullying and job alienation, International Journal of Organizational Analysis, 24(2), 291-314.

Blauner, R. (1964). Alienation and freedom: The factory worker and his industry. Chicago, IL: Chicago U. Press.

Brockner, J. (1983). Love self-esteem and behavioral plasticity: Some implications. In L. Wheeler \& P. R. Shaver (Eds.), Review of personality and social psychology, (Vol. 4: pp. 237-271). Beverly Hills, CA: Sage.

Brockner, J. (1988). Self-esteem at work: Research, theory, and practice. Lexington Books/D. C. Heath and Com.

Brondolo, E., Eftekharzadeh, P., Clifton, C., Schwartz, J. E., \& Delahanty, D. (2018). Workrelated trauma, alienation, and posttraumatic and depressive symptoms in medical examiner employees. Psychological Trauma: Theory, Research, Practice, and Policy, 10(6), 689-697.

Burton, J. P., Hoobler, J. M., \& Kernan, M. C. (2011). When research setting is important: The influence of subordinate self-esteem on reactions to abusive supervision. Organization Management Journal, 8(3), 139-150.

Burton, J.P., Hoobler, J.M., \& Scheuer, M. L. (2012). Supervisor workplace stress and abusive supervision: the buffering effect of exercise. Journal of Business and Psychology, 27, 271-279.

Chi, N.W., Chen, Y.C., Huang, T.C., \& Chen, S.F. (2018). Trickle-down effects of positive and negative supervisor behaviors on service performance: The roles of employee emotional labor and perceived supervisor power. Human Performance, 31(1), 55-75.

Chiaburu, D.S., Thundiyil, T., \& Wang, J. (2014). Alienation and its correlates: A metaanalysis. European Management Journal, 32, 24-36.

Cohen, J. (1988). Statistical Power Analysis for the Behavioral Sciences (2nd ed.). NJ, Lawrence Erlbaum Associates, Hillsdale.

Dean, D. G. (1961). Alienation: Its meaning and measurement. American Sociological Review, 26(5), 753-758.

DiPietro, R. B., \& Pizam, A. (2008). Employee alienation in the quick service restaurant industry. Journal of Hospitality\& Tourism Research, 32(1), 22-39.

Eisenberger, R., Lynch, P., Aselage, J., \& Rohdieck, S. (2004). Who takes the most revenge? Individual differences in negative reciprocity norm endorsement. Personality and Social Psychology Bulletin, 30, 1-13.

Ekrot, B., Rank, J., \& Gemünden, H.G. (2016). Antecedents of project managers' voice behavior: The moderating effect of organization-based self-esteem and affective 
organizational commitment. International Journal of Project Management, 34,10281042.

Fatima, T., Majeed, M., \& Shah, S. Z. A. (2018). Jeopardies of aversive leadership: A conservation of resources theory approach. Frontiers in Psychology, 9, 1935. doi: 10.3389/fpsyg.2018.01935.

Finney, T. G., Finney, R. Z., \& Maes, J. D. (2018). Abusive supervision and employee alienation: A exploratory study. Journal of Organizational Psychology, 18(1), 78-87.

Fornell, C., \& Larcker, D. F. (1981). Evaluating structural equation models with unobservable variables and measurement error. Journal of Marketing Research, 18(1), 39-50.

García-Cabrera, A. M., \& García-Barba Hernández, F. (2014). Differentiating the three components of resistance to change: The moderating effect of organization-based self-esteem on the employee involvement-resistance relation. Human Resource Development Quarterly, 25(4), 441-469.

Gardner, D. G., \& Pierce, J. L. (1998). Self-esteem and self-efficacy within the organizational context: An empirical examination. Group \& Organization Management, 23(1), 48-70.

Geisser, S. (1974). A predictive approach to the random effect model. Biometrika, 61(1), 101107.

Gouldner, A. W. (1960). The norm of reciprocity: A preliminary statement. American Sociological Review, 25(2), 161-178.

Gürlek, M. (2020a). Aşırı iş yükü nasıl etik dışı davranışları etkiler? Ücret tatminsizliğinin aracılık rolü. İş Ahlakı Dergisi. Doi: 10.12711/tjbe.2020.13.1.0141

Gürlek, M. (2020b). Shedding light on the relationships between Machiavellianism, career ambition, and unethical behavior intention. Ethics $\mathcal{E}$ Behavior. https://doi.org/10.1080/10508422.2020.1764846

Gürlek, M., \& Uygur, A. (2020). Service-oriented high performance human resource practices and employee service performance: A test of serial mediation and moderation models. Journal of Management $\mathcal{E}$ Organization. https://doi.org/10.1017/jmo.2020.8

Haar, J. M., de Fluiter, A., \& Brougham, D. (2016). Abusive supervision and turnover intentions: The mediating role of perceived organizational support. Journal of Management \& Organization, 22, 139-153.

Hair, J. F., Hult, G. T. M., Ringle, C. M., \& Sarstedt, M. (2014). A primer on partial least squares structural equations modeling (PLS-SEM). London: Sage Publications.

Hair, J.F., Hult, G. T., Ringle, C. M., \& Sarstedt, M. (2017). A primer on partial least squares structural equation modeling (PLS-SEM) (2nd ed.). London: Sage Publication.

Han, R., Ya-Ling, X., \&Wei-Zheng, C. (2013). Abusive supervision and employees' work alienation: Comparative analysis of migrant workers and urban workers.20th Annual Conference Proceedings of the International Conference on Management Science and Engineering (pp. 1332-1340). IEEE: China.

Harris, L. C., \& Ogbonna, E. (2002). Exploring service sabotage the antecedents, types and consequences of frontline, deviant, antiservice behaviors. Journal of Service Research, 4(3), 163-183.

Harris, L. C., \& Ogbonna, E. (2006). Service sabotage: A study of antecedents and consequences. Journal of the Academy of Marketing Science, 34(4), 543-558.

Harris, L.C., \& Ogbonna, E. (2010). Hiding customer complaints: Studying the motivations and forms of service employees' complaint concealment behaviours. British Journal of Management, 21, 262-279. 
Harris, K. J., Harvey, P., \& Kacmar, K. M. (2011). Abusive supervisory reactions to coworker relationship conflict. The Leadership Quarterly, 22(5), 1010-1023.

Henseler J., \& Fassott G. (2010). Testing moderating effects in PLS Path Models: An illustration of available procedures. In V. Esposito Vinzi, W. Chin, J. Henseler, H. Wang (Eds.), Handbook of Partial Least Squares. Springer Handbooks of Computational Statistics (pp. 713-735). Hidelberg, Berlin: Springer.

Henseler, J., Ringle, C. M., \& Sarstedt, M. (2015). A new criterion for assessing discriminant validity in variance-based structural equation modeling. Journal of the Academy of Marketing Science, 43(1), 115-135.

Henseler, J., Ringle, C. M., \& Sinkovics, R. R. (2009). The use of partial least squares path modeling in international marketing. In R. R. Sinkovics, \& P. N. Ghauri (Eds.), New challenges to international marketing (pp. 277-319). Bingley: Emerald Group Publishing Limited.

Hirschfeld, R. R., \& Feild, H. S. (2000). Work centrality and work alienation: Distinct aspects of a general commitment to work. Journal of Organizational Behavior, 21, 789-800.

Hobfoll, S. E. (1989). Conservation of resources: A new attempt at conceptualizing stress. American Psychologist, 44, 513-524.

Hoffmann, A., \& Birnbrich, C. (2012). The impact of fraud prevention on bank- customer relationships: An empirical investigation in retail banking. International Journal of Bank Marketing, 30(5), 390-407.

Hon, A. H. Y., \& Lu, L. (2016). When will the trickle-down effect of abusive supervision be alleviated? The moderating roles of power distance and traditional cultures. Cornell Hospitality Quarterly, 57(4), 421-433.

Hoobler, J. M., \& Brass, D. J. (2006). Abusive supervision and family undermining as displaced aggression. Journal of Applied Psychology, 91(5), 1125-1133.

Hui, C., \& Lee, C. (2000). Moderating effects of organization-based self-esteem on organizational uncertainty: Employee response relationships. Journal of Management, 26(2), 215-232.

Hussain, I., \& Sia, S.K. (2017). Power distance orientation dilutes the effect of abusive supervision on workplace deviance. Management and Labour Studies, 42(4) 293-305.

Jermier, J. (1988). Sabotage at work. In N. DiTamaso (Ed.), Research in the sociology of organizations (Vol. 6, pp. 101-135). Greenwich, CT: JAI.

Jian, Z., Kwan, H. K., Qiu, Q., Liu, Z. Q., \& Yim, F. H. (2012). Abusive supervision and frontline employees' service performance. The Service Industries Journal, 32(5), 683698.

Jung, H. S., \& Yoon, H. H. (2014). Antecedents and consequences of employees' job stress in a foodservice industry: Focused on emotional labor and turnover intent. International Journal of Hospitality Management, 38, 84-88.

Kanten, P., Kanten, S., Yeşiltaş, M., \& Yaşlığlu, M. (2015). Ücret adaletinin hizmet süreçlerini sabote etme ve sosyal kaytarma davranışları üzerindeki etkisinde ücret eşitliği algısının rolü. 23. Ulusal Yönetim ve Organizasyon Kongresi, Muğla.

Kanungo, R. N. (1982). Work alienation. New York: Praeger.

Kiazad, K., Restubog, S. L. D., Zagenczyk, T. J., Kiewitz, C., \& Tang, R. L. (2010). In pursuit of power: The role of authoritarian leadership in the relationship between supervisors' Machiavellianism and subordinates' perceptions of abusive supervisory behavior. Journal of Research in Personality, 44, 512-519.

Kock, N. (2015). Common method bias in PLS-SEM: A full collinearity assessment approach. International Journal of e-Collaboration, 11(4), 1-10. 
Lee, J. J., \& Ok, C. M. (2014). Understanding hotel employees' service sabotage: Emotional labor perspective based on conservation of resources theory. International Journal of Hospitality Management, 36, 176-187.

Li, S., \& Chen, Y. (2018). The relationship between psychological contract breach and employees' counterproductive work behaviors: the mediating effect of organizational cynicism and work alienation. Frontiers in Psychology, 9, 1273. doi: 10.3389/fpsyg.2018.01273

Liu, J., Kwong Kwan, H., Wu, L. Z., \& Wu, W. (2010). Abusive supervision and subordinate supervisor-directed deviance: The moderating role of traditional values and the mediating role of revenge cognitions. Journal of Occupational and Organizational Psychology, 83(4), 835-856.

Lyu, Y., Zhu, H., Zhong, H. J., \& Hu, L. (2016a). Abusive supervision and customeroriented organizational citizenship behavior: The roles of hostile attribution bias and work engagement. International Journal of Hospitality Management, 53, 69-80.

Lyu, Y., Zhou, X., Li, W., Wan, J., Zhang, J., \& Qiu, C. (2016b). The impact of abusive supervision on service employees' proactive customer service performance in the hotel industry. International Journal of Contemporary Hospitality Management, 28(9), 1992-2012.

Marx, K. (1963). Early writings (T. B. Bottomore, Trans.). New York: McGraw-Hill. (Original work published 1844)

Marx, K. (1969). Theories of Surplus Value, Part I. London: Lawrence \& Wishart.

Merli, R., Preziosi, M., Acampora, A., Lucchetti, M.C., \& Ali, F. (2019). The impact of green practices in coastal tourism: An empirical investigation on an eco-labelled beach club. International Journal of Hospitality Management, 77, 471-482.

Merton, R. K. (1938). Social structure and anomie. American sociological review, 3(5), 672-682. Ministry of Culture and Tourism. (2019). The list of hotels with tourism operation license. Retrieved December 16, 2019, from http://yigm.kulturturizm.gov.tr/TR,9579/turizm-tesisleri.html

Ministry of Culture and Tourism. (2020). Turizm İstatistikleri. Retrieved December 16, 2019, from https://yigm.ktb.gov.tr/TR-9851/turizm-istatistikleri.html

Mitchell, M. S., \& Ambrose, M. L. (2007). Abusive supervision and workplace deviance and the moderating effects of negative reciprocity beliefs. Journal of Applied Psychology, 92(4), 1159-1168.

Mitchell, R.G. (1984). Alienation and deviance: Strain theory reconsidered. Sociological Inquiry, 54(3),330-345.

Nair, N., \& Vohra, N. (2009). Developing a new measure of work alienation. Journal of Workplace Rights, 14(3),293-309.

Nair, N., \& Vohra, N. (2012). The concept of alienation: Towards conceptual clarity. International Journal of Organizational Analysis, 20(1), 25-50.

O'Donohue, W., \& Nelson, L. (2014). Alienation and managing human resources. International Journal of Organisational Analysis, 22(3),301-316.

Özbek, M. F. (2011). Örgüt içerisindeki güven ve işe yabancılaşma ilişkisinde örgüte uyum sağlamanın aracı rolü. Demirel Üniversitesi İktisadi ve İdari Bilimler Fakültesi Dergisi, 16(1), 231-248.

Özer, Ö., Uğurluoğlu, Ö., Saygılı M., \& Sonğur, C. (2019). The impact of work alienation on organizational health: A field study in health sector. International Journal of Healthcare Management, 12(1), 18-24.

Pan, W., Sun, L., Sun, L. Y., Li, C., \& Leung, A. S. M. (2018). Abusive supervision and joboriented constructive deviance in the hotel industry: Test of a nonlinear mediation 
and moderated curvilinear model. International Journal of Contemporary Hospitality Management, 30(5), 2249 - 2267.

Park, J., \& Kim, H.J. (2019). How and when does abusive supervision affect hospitality employees' service sabotage? International Journal of Hospitality Management, 83,190-197.

Pierce, J. L., \& Gardner, D. G. (2004). Self-esteem within the work and organizational context: A review of the organization-based self-esteem literature. Journal of Management, 30(5), 591-622.

Pierce, J. L., Gardner, D. G., Cummings, L. L., \& Dunham, R. B. (1989). Organization-based self-esteem: Construct definition, operationalization, and validation. Academy of Management Journal, 32, 622-648.

Pierce, J. L., Gardner, D. G., Dunham, R. B., \& Cummings, L. L. (1993). Moderation by organization-based self-esteem of role condition-employee response relationships. Academy of Management Journal, 36(2), 271-288.

Podsakoff, P. M., MacKenzie, S. B., Lee, J. Y., \& Podsakoff, N. P. (2003). Common method biases in behavioral research: A critical review of the literature and recommended remedies. Journal of Applied Psychology, 88(5), 879-903.

Preacher, K.J., \& Hayes, A.F. (2008). Asymptotic and resampling strategies for assessing and comparing indirect effects in multiple mediator models. Behavior Research Methods, 40(3), 879-891.

Richman, J. A., Flaherty, J. A., \& Rospenda, K. M. (1996). Perceived workplace harassment experiences and problem drinking among physicians: Broadening the stress/alienation paradigm. Addiction, 91(3), 391-403.

Ringle, C. M., Wende, S., \& Becker, J.M. (2015). SmartPLS 3. Boenningstedt: SmartPLS $\mathrm{GmbH}$, http://www.smartpls.com.

Rodríguez-Victoria, O. E., Puig, F., \& González-Loureiro, M. (2017). Clustering, innovation and hotel competitiveness: Evidence from the Colombia destination. International Journal of Contemporary Hospitality Management, 29(11), 2785-2806.

Rousseau, M.B., Eddleston, K.A., Patel, P.C., \& Kellermanns, F.W. (2014). Organizational resources and demands influence on workplace bullying. Journal of Managerial Issues, 3, 286-313.

Santas, G., Isik, O., \& Demir, A. (2016). The effect of loneliness at work; work stress on work alienation and work alienation on employees' performance in Turkish health care institution. South Asian Journal of Management Sciences, 10(2), 30-38.

Schyns, B. \& Schilling, J. (2013). How bad are the effects of bad leaders? A meta-analysis of destructive leadership and its outcomes. The Leadership Quarterly, 24, 138-158.

Shantz, A., Alfes, K., Bailey, C., \& Soane, E. (2015). Drivers and outcomes of work alienation: Reviving a concept. Journal of Management Inquiry, 24(4), 382-393.

Shantz, A., Alfes, K., \& Truss, K. (2014) Alienation from work: Marxist ideologies and twenty-first-century practice. The International Journal of Human Resource Management, 25(18), 2529-2550.

Seeman, M. (1959). On the meaning of alienation. American Sociological Review, 24(6), 783791.

Stone, M. (1974). Cross-validatory choice assessment of statistical predictions. Journal of the Royal Statistical Society, 36, 111-147.

Tepper, B. J. (2000). Consequences of abusive supervision. Academy of Management Journal, 43(2), 178-190. 
Tepper, B. J., Henle, C. A., Lambert, L. S., Giacalone, R. A., \& Duffy, M. K. (2008). Abusive supervision and subordinates' organization deviance. Journal of Applied Psychology, 93(4), 721-732.

Thau, S., \& Mitchell, M.S. (2010). Self-gain or self-regulation impairment? Tests of competing explanations of the supervisor abuse and employee deviance relationship through perceptions of distributive justice. Journal of Applied Psychology, 95(6), 1009-1031.

$\mathrm{Tu}, \mathrm{M} .$, Bono, J. E., Shum, C., \& LaMontagne, L. (2018). Breaking the cycle: The effects of role model performance and ideal leadership self-concepts on abusive supervision spillover. Journal of Applied Psychology, 103(7), 689-702.

Twining, J. E. (1980). Alienation as a social process. The Sociological Quarterly, 21(3), 417428.

Ülbeği, İ. D., Özgen, H. M., \& Özgen, H. (2014). Türkiye' de istismarcı yönetim ölçeğinin uyarlaması: Geçerlilik ve güvenilirlik analizi. Ç.Ü. Sosyal Bilimler Enstitüsü Dergisi, 23(1), 1-12.

Vogel, R. M., \& Mitchell, M. S. (2017). The motivational effects of diminished self-esteem for employees who experience abusive supervision. Journal of Management, 43(7), 2218-2251.

Wang, W., Mao, J., Wu, W., \& Liu, J. (2012). Abusive supervision and workplace deviance: The mediating role of interactional justice and the moderating role of power distance. Asia Pacific Journal of Human Resources, 50, 43-60.

Xiaqi, D., Kun, T., Chongsen, Y., \& Sufang, G. (2012). Abusive supervision and LMX. Chinese Management Studies, 6(2), 257-270.

Xu, E., Huang, W., Lam, C.K., \& Miao, Q. (2012). Abusive supervision and work behaviors: The mediating role of LMX. Journal of Organizational Behavior, 33, 531-543.

Yeşiltaş, M., \& Gürlek, M. (2019). Understanding the Nature of Deviant Workplace Behaviors. In Ş. Aydin, B. Dedeoglu, \& Ö. Çoban (Eds.), Organizational Behavior Challenges in the Tourism Industry (pp. 305-326). Hershey, PA: IGI Global. doi:10.4018/978-1-7998-1474-0.ch017.

Yeşiltaş, M., \& Tuna M. (2018). The effect of ethical leadership on service sabotage. The Service Industries Journal, 38(15-16), 1133-1159.

Zhao, H., \& Guo, L. (2019). Abusive supervision and hospitality employees' helping behaviors: The joint moderating effects of proactive personality and ability to manage resources. International Journal of Contemporary Hospitality Management, 31(4), 1977-1994.

Zhao, X., Lynch Jr., J.G., \& Chen, Q. (2010) Reconsidering Baron and Kenny: Myths and truths about mediation analysis. Journal of Consumer Research, 37, 197-206.

Zhou, X., Ma, J., \& Dong, X. (2018). Empowering supervision and service sabotage: A moderated mediation model based on conservation of resources theory. Tourism Management, 64, 170-187.

Zoghbi-Manrique-De-Lara, P., \& Viera-Armas, M. (2019). Using alienation at work to explain why managers' dishonesty does not lead to firm performance. European Management Review, 16, 273-284.

https://webpower.psychstat.org/models/kurtosis 